\title{
OCULAR SARCOMA WITH WIDE EXTENSION, INVOLVING BRAIN AND SPINAL CORD*
}

BY

\author{
Humphrey Neame \\ LONDON
}

IT is rare for penetration of the globe to take place in cases of epibulbar sarcoma. Still more rare is it for this to occur without extensive damage to the form of the eyeball. The present paper is an account of a case in which this occurred, and a review of the literature which bears on the subject.

In May, 1919, a man named F. B., aged 53 years, felt, according to his statements, slight irritation beneath the upper lid of the left eye. He noticed this first while riding a cycle, and on the same day he found that there was a small swelling beneath the lid, on the eye just above the "coloured part" of the eye. The swelling was about the size of a split pea when he first noticed it. He did not feel any change in the sight of the left eye until December, 1919, although the lump increased steadily in size.

In July, 1919, B. attended the Royal London Ophthalmic Hospital under the care of Sir John Herbert Parsons. At this date, examination carried out at the hospital revealed, according to the notes, that the vision was as follows:- $-\mathrm{R}$. eye, $6 / 36$, c. $-2.5=6 / 5$. L. eye, $5 / 60$, c. $-3.5=6 / 6$. There was noted then "solid oedema" round the cornea, especially above.

A history was obtained from B. of ulceration of the palate followed by perforation, and falling in of the nose to some extent. The Wassermann reaction was carried out by Dr. S. H. Browning, and was found to be positive, on October 15, 1919.

Internal administration of mercuric chloride was adopted, and in November and December, 1919, and January, 1920, intravenous injections of novarsenobillon were given, with a dosage of from 0.3 up to 0.9 gram, which totalled 4.05 grams.

In January the iris was greenish, the pupil-irregular, and the condition of oedema around the cornea was unchanged. There were also vitreous opacities.

In July, 1920, the notes reveal that the oedema was as before, that there was much "K.P.," and that a small brown-red mass was visible in the lower part of the anterior chamber in front of the iris. In September the tension of the left eye was referred to as $\mathrm{T} .+1$.

In March, 1921, at Sir John Herbert Parsons's invitation, B. was seen by the writer. B. stated then that the sight of the left eye began to fail in December, 1919. In March, 1921, there was merely perception of light with the left eye. There was then

* Case described at a meeting of the Ophthalmic Section of the Royal Society of Medicine in the first quarter of 1922. 
marked swelling of the sub-conjunctival tissue and overlapping of the conjunctiva over the corneal margin all round (Fig. 1). This gave an appearance of proptosis, but careful measurements taken showed the plane of the cornea, on the right as on the left, to be 8 centimetres anterior to the mandibular condyle. The conjunctiva covering the swelling, was tense, smooth, glistening, and adherent to the swelling. It was also diffusely reddened, and showed several vessels coursing over the swelling towards the cornea. The swelling was firm throughout its extent.

The cornea, encroached upon as described, was markedly hazy throughout, and this appeared to be superficial and deep. No

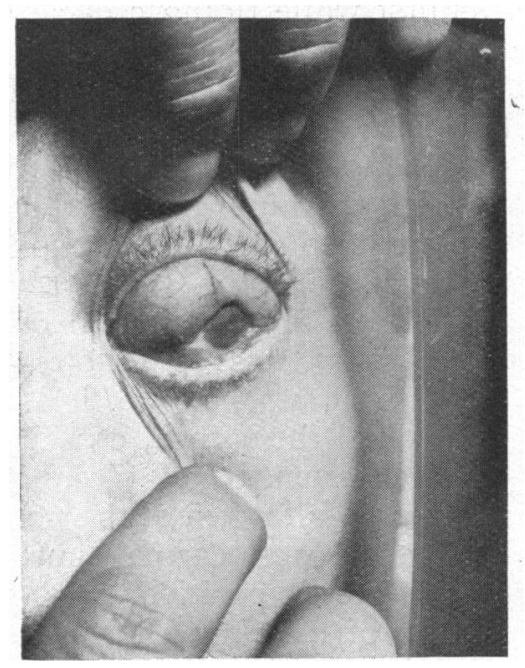

FIG. 1.

Photograph of the eye before enucleation.

Shows the prominence of the tumour particularly above the cornea.

vessels were seen in its substance or on its surface. There was a small brown-red patch dimly visible in the lower part of the anterior chamber, which was taken to be a hyphaema.

No details were visible of iris or lens, and there was no red reflex. Vision of the left eye was perception of light.

The globe was excised on March 24, 1921, and placed in 4 per cent. formaldehyde.

\section{Collateral investigation}

Fracture.-A fracture of the right tibia was sustained late in 1919. On the admission of B. to the Royal London Ophthalmic Hospital the fracture was found to be united so that the patient could walk with slight difficulty. In order to exclude the 
possibility that the fracture was associated with a new growth of the bone of the nature of a plasmacytoma, enquiry was made of Mr. Charles Gibbs, under whose care the patient had been. The latter kindly reported that the fracture was "a long oblique fracture of the tibia, slightly spiral, united in good position. No suggestion of new growth at all; normal tibia otherwise. Fibula not fractured, is thickened opposite the fracture, and above and below it, with new periosteal bone, probably compensatory. September 27, 1921."

Blood.-In September, 1921, a blood examination carried out by Dr. S. H. Browning showed a normal white cell differential

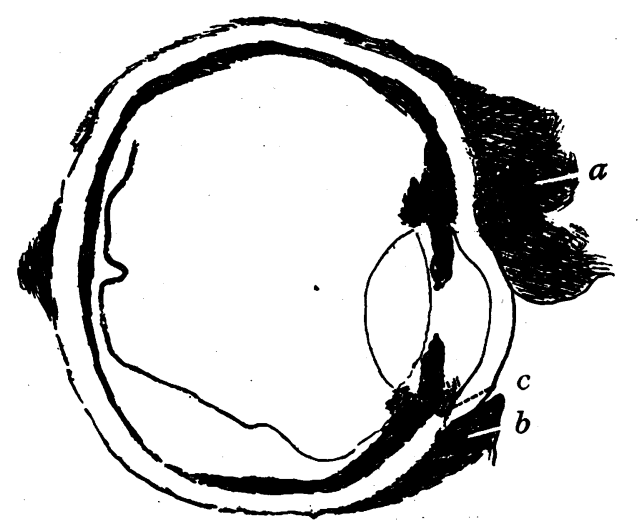

FIG. 2.

Drawing of section of the eye. Sagittal plane.

(a) The growth overlapping the upper part of the cornea.

(b) The growth below the cornea.

(c) Track of growth connecting the epibulbar part with that in the Canal of Schlemm.

count. A further blood count carried out in December, 1921, revealed an excess of large hyaline cells only.

$$
\begin{aligned}
& \begin{array}{lllll}
\text { Polymorphonuclear } & \ldots & \ldots & \ldots & 50 \text { per cent. }
\end{array} \\
& \begin{array}{lllllll}
\text { Small lymphocyte } & \ldots & \ldots & \ldots & 10 & , & ,
\end{array}
\end{aligned}
$$

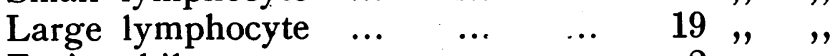

$$
\begin{aligned}
& \begin{array}{llllll}
\text { Eosinophile } & \ldots & \ldots & \ldots & 2,, & , \text {, }
\end{array} \\
& \begin{array}{llllll}
\text { Large hyaline } & \ldots & \ldots & \ldots & 19 &
\end{array} \\
& \text { (110 counted) } \overline{100},,,
\end{aligned}
$$

\section{Examination of excised eyeball}

Macroscopic. Formalin fixation.-The eyeball was bisected vertically (Fig. 2). Externally the globe showed little more than 
was visible clinically. The main swelling was present around the corneal margin, and particularly the upper part.

The cut surface revealed a homogeneous dense, firm, white mass surrounding and encroaching upon the cornea. The mass was covered anteriorly by smooth glistening conjunctiva, and in its cut surface was decidedly larger above the cornea-superiorly than inferiorly - and in the former situation measured $14 \mathrm{~mm}$. antero-posteriorly, and up to $6 \mathrm{~mm}$. in thickness.

The extent of cornea that was visible from in front measured 8 by $8 \mathrm{~mm}$., was densely nebulous, and appeared slightly thicker

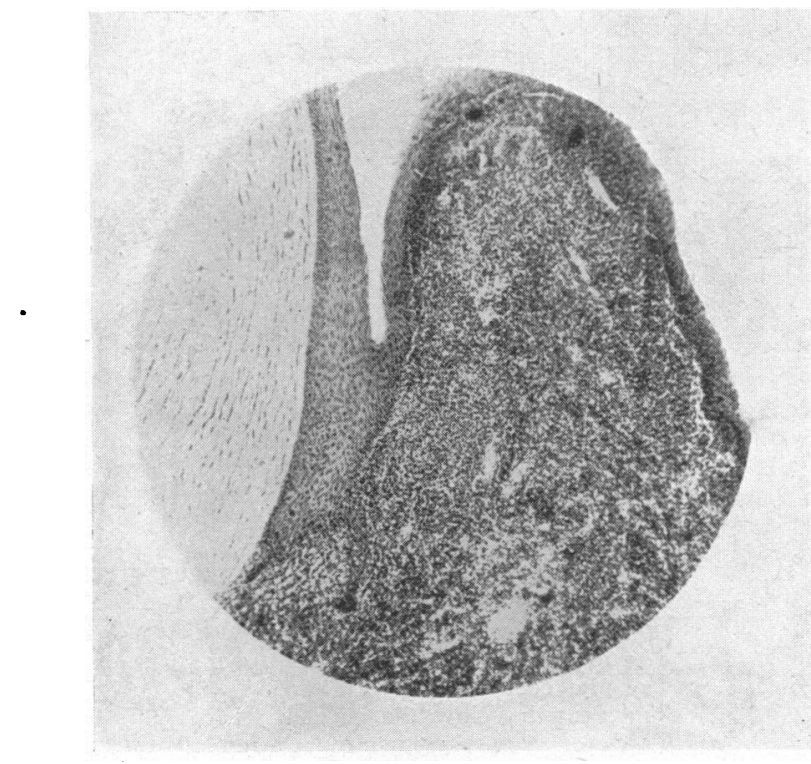

Fig. 3.

Microphotograph of the growth overlapping the lower part of the cornea. This corresponds with "b" in Fig. 2.

in section than normal. The iris and ciliary body were much thickened. The anterior chamber contained a small amount of flocculent material, and in the lower part a stratum of brown substance. The lens had a normal appearance. The retina was in situ. The choroid was much swollen, and at the posterior pole was almost as thick as the sclerotic on section. The vitreous cavity was occupied by pale greenish substance of firm elastic consistency.

Microscopic.-Half of the globe was embedded in celloidin. Sections were stained with Ehrlich's haematoxylin and eosin. In these sections the mass of tissue overlying the periphery of the 
cornea is seen to have split the corneal epithelium into two layers for a short distance and to have derived its covering partly from the outer layer of this and partly from the conjunctiva. In some parts this covering epithelium is thickened and contains cells which have the appearance of prickle cells. (The general distribution of the new formation is seen in Fig. 2, and its relation to the cornea near the lower part of the limbus in Fig. 3.) The corneal epithelium, where it is overlapped by the mass, has its outer layers flattened and in places changed into much elongated cells. Bowman's membrane is intact, and a slight invasion of the substantia propria is seen to have occurred at the limbus and of the superficial layers of the sclera posterior to this. The substantia propria is elsewhere unaffected except for a slight increase of cellular elements near the centre of the deeper layers. Descemet's membrane is intact, and the endothelium is visible throughout except where it is obscured by a cellular deposit on its deep surface. The deposit is present as a thin layer of cells all over the greater part of the deep surface of the cornea. The cells are of a similar character to those forming the main mass, whose minute structure will be described later.

The anterior chamber is, in the sections, up to $3 \mathrm{~mm}$. in depth, and contains in addition to the deep corneal deposits, a mass of cells projecting upwards from the inferior angle almost to the centre of the chamber, with some faintly eosinophilic hyaline material anterior and posterior to this cell mass. The angle of the chamber in its upper part also contains detached groups of cells, and others upon the ligamentum pectinatum iridis, which appear to be continuous with similar cells that infiltrate the ligamentum. Through the spaces in the ligamentum pectinatum the cells are seen to extend into the iris and ciliary body, and also into the area that should be occupied by the canal of Schlemm. No endothelial lining can be detected as representing this canal, so dense is the cell infiltration. The iris and ciliary.body are both densely infiltrated throughout with similar cells, almost to the disappearance of normal structures. In the iris traces of the sphincter pupillae can be seen, and in the ciliary body fibres of the ciliary muscle can be detected. The pigment epithelium of the iris is intact, and the epithelium covering the ciliary processes and that of the pars ciliaris can be seen, although these latter are partly obscured by the cell infiltration within the ciliary body, and by layers of cells upon its surface. The lens structure is normal.

The remaining structures within the globe will be described later. The sclera and the continuity of the new cell formation without and within the eye will now be considered.

The sclera is almost entirely enclosed within a coat of closelypacked cells. This covering is continued backwards from the 
masses of cells seen in the sections overlapping the superior and inferior parts of the cornea (Fig. 2). It is thickest where a vena vorticosa is sectioned near the equator and posteriorly around some posterior ciliary vessels. In both these regions there is a thick dense cellular mass surrounding the several vessels.

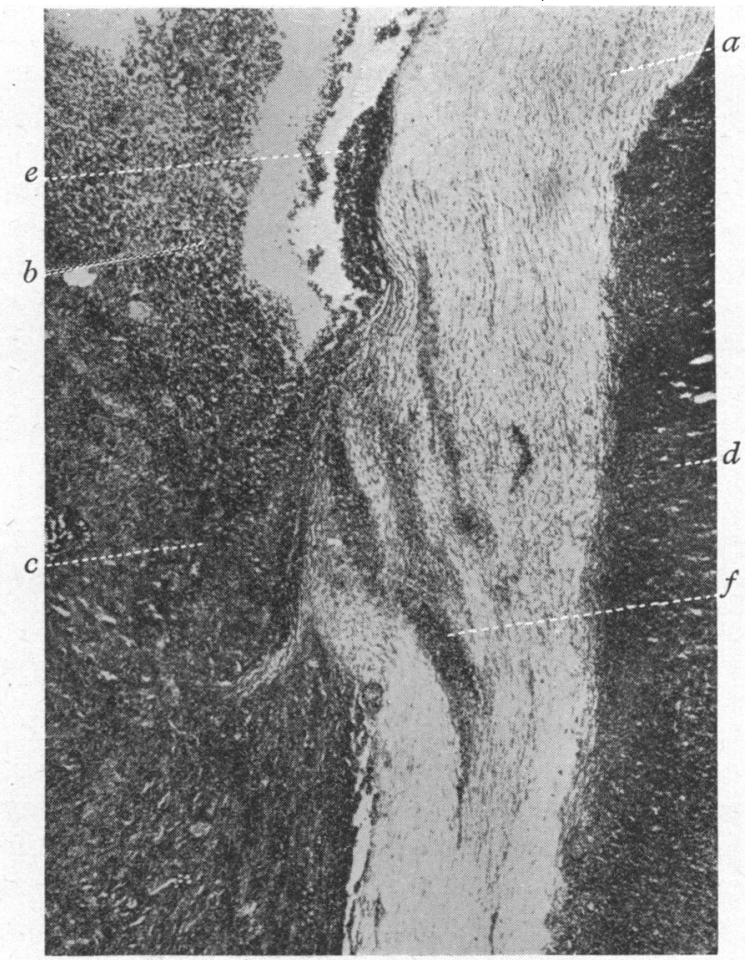

Fig. 4.

Microphotograph, magnification 30 times.

(a) Cornea.

(b) Root of iris densely infiltrated with growth

(c) Ciliary body densely infiltrated with growth.

(d) Epibulbar growth over the lower part of the cornea.

(e) Growth cells on the posterior surface of the cornea.

(f) Track of growth connecting the epibulbar with the intra-ocular part of the growth. Corresponds with " $c$ " in Fig. 2.

The optic nerve cut in transverse section immediately posterior to the globe shows an abundance of cells surrounding the posterior ciliary vessels and in the loose connective tissue outside the dural sheath. These cells show long spindle or rod shaped nuclei.

Wherever, if the sclera were normal, it would be expected to 
show its various perforating vessels, there it encloses strands or masses of cells. From the site of the canal of Schlemm in front, outwards and backwards extend strands and masses of cells. (Fig. 4.) Similarly near the equator and near the' posterior pole roadways crammed with cells can be traced in successive sections extending between the choroid and the exterior cell masses. Nowhere does there appear to be any wide breach of the defences such as occurs in the majority of specimens of penetrating epibular sarcoma that have been described. Rather there seems to have been a more sinister and less dramatic entry through almost every available portal.

Within the vitreous are small clusters of cells scattered about in its anterior part in the region of the pars ciliaris retinae and the anterior part of the retina.

The retina is in situ except for a small area in the inferior part of the globe, where the detachment took place in the course of fixation and dehydration of the specimen. It is everywhere normal apart from some delicate cystic degeneration most marked in the ganglion-cell and nerve-fibre layers. Nowhere is there any invasion or involvement of the retina by the new cell formation.

'The choroid throughout is much thickened and intensely infiltrated with cells of similar appearance to those in other parts of the globe. The delicate structure of the choroid is entirely obliterated, and only the medium-sized and larger vessels are seen. As already mentioned, this cell infiltration can be traced in some of the sections along tracks through the sclera at the usual sites occupied by venae vorticosae and posterior ciliary vessels (Fig. 5).

The minute structure of the new formation.-The growth everywhere is composed of closely-packed masses of cells, freely supplied with delicate capillaries. With Zeiss D. objective and No. 4 eye-piece the nuclei-are seen to be round or oval, or of slightly irregular outline. For the most part they are round. The cell protoplasm is not well differentiated. There are also a number of rod shaped or spindle-like nuclei which stain less darkly with haematoxylin. These elongated nuclei are twice or even three times the length of the average round nucleus. The cells are frequently found to be arranged in double rows of six or eight nuclei in each, with a narrow space between the two rows, which gives the appearance of tubule formation. In other places there are incomplete rings of cells as of tubules cut transversely, which simulate to a slight degree the rosettes of glioma of the retina. These pseudo-tubules have no endothelial lining. Some of the more delicate capillaries have at first sight a similar appearance, but they are distinguished by the definite lining of flat endothelial cells with the cells of the new formation arranged along the outer 
surface of this lining. Examination with the $1 / 12$ oil immersion objective reveals the presence of fairly frequent mitotic figures.

A small slice was cut off from the celloidin block, to include the smaller inferior portion of growth where it projected over the cornea, and the infiltrated iris. This was re-embedded by

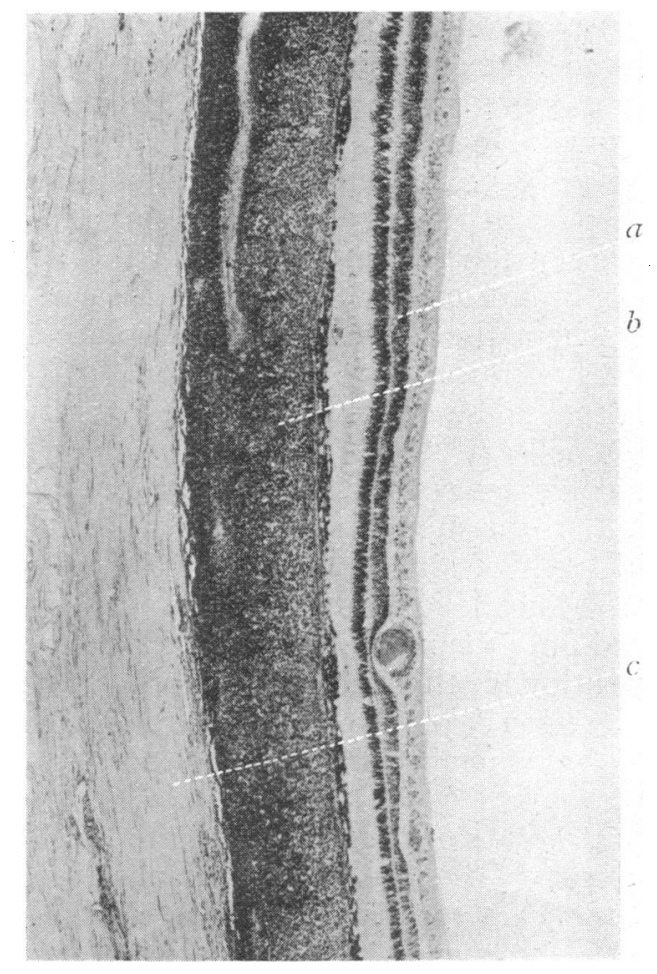

Fig. 5.

Microphotograph, magnification 30 times.

(a) Retina.

(b) Choroid densely infiltrated with growth.

(c) Sclera.

This represents part of the coats of the globe near the posterior pole.

Jordan's method, and thin sections were cut and stained by Weigert's iron haematoxylin and van Gieson's stain.

Van Gieson's stain shows a very limited amount of collagen fibre, and this chiefly in the immediate neighbourhood of the covering conjunctival epithelium, or at the outer surface of the sclera or limbus where the cells are seen to be infiltrating these tissues and breaking up, or spreading between their lamellae. It 
seems probable that the bulk of this collagen fibre is derived from the infiltrated structures. In one part, near the surface of the extra-ocular portion a very marked proliferation of rod shaped and spindle-shaped cells is seen. Many of these nuclei are as long as from three to five times the diameter of an average circular nucleus. Many are curved. In this particular area red corpuscles are seen to occupy small capillaries which are particularly abundant, and corpuscles are also apparently lying among some of the cells of the new formation.

Further progress of the case.-On June 16, 1921, there was a swelling in the socket, beneath the well-healed conjunctiva (see stereo-photograph, Fig. 6). The conjunctiva was smooth and

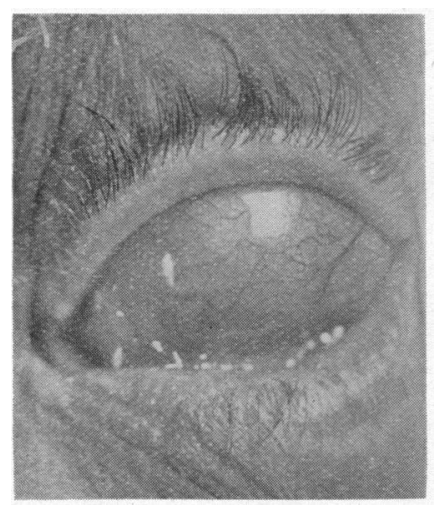

Stereo-photograph of the socket with the lids drawn back, before the operation of exenteration of the orbit was performed. Shows the prominent mass which filled the orbit.

glistening, and contained an abundance of well-filled blood vessels, clearly shown in the photograph. The swelling was ovoid and about $2 \mathrm{~cm}$. in horizontal diameter and $1.3 \mathrm{~cm}$. vertically. It was firm, slightly elastic, and movable within the orbit to a moderate degree.

Apart from the swelling in the left orbit the patient complained of no symptoms. The abdomen was examined, but revealed to palpation no presence of any abnormal swelling, and to percussion no unusual area of dulness.

On July 6, 1921, the operation of exenteration of the orbit was carried out by Sir John Herbert Parsons. The orbit healed satisfactorily. The patient was seen by the writer in the middle of February, 1922, and appeared quite well, with no sign of orbital recurrence.

Pathological examination of the tissue removed from the orbit. - The mass was composed of the edges of the eyelids and a margin 
of normal skin, the palpebral conjunctiva and that covering the mass, a quantity of fibro-fatty tissue and within the latter an eggshaped mass of elastic consistency measuring 2.5 by 1.7 by $1.5 \mathrm{cms}$. On one surface this mass was covered by a smooth glistening membrane continuous with the palpebral conjunctiva, on the other side it was not clearly demarcated from the neighbouring tissues. There were a few subsidiary nodules in connection with the main mass. The cross-section of the mass showed an almost dead-white finely granular surface, with a few pale redbrown streaks and spots mainly near its periphery.

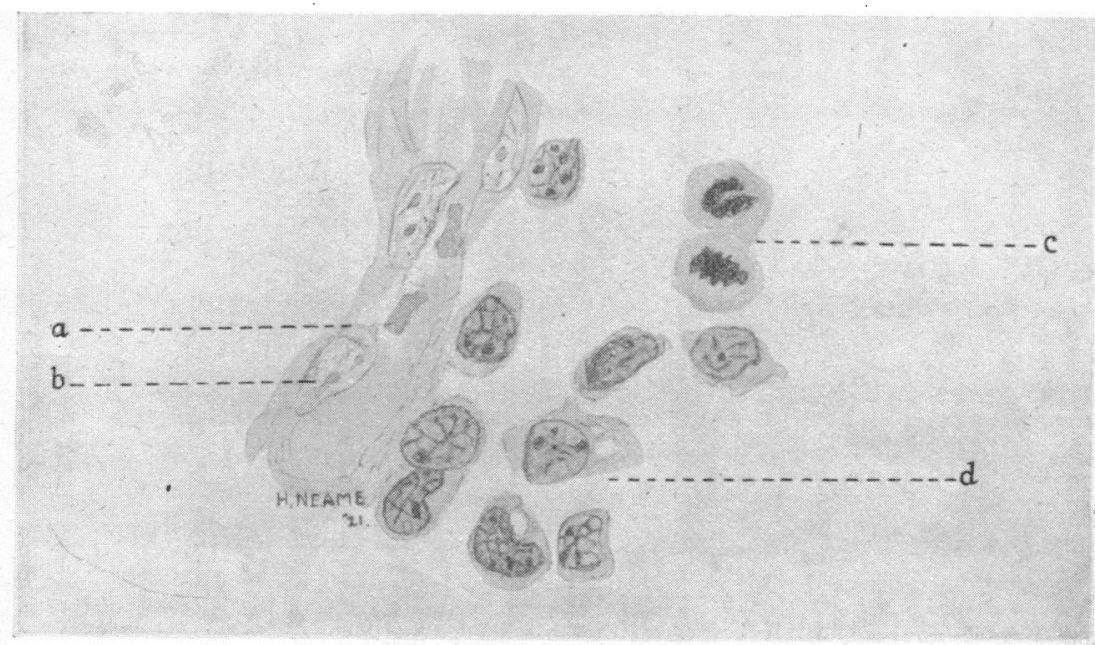

Fig. 7.

Drawing of a section of the orbital recurrence as seen with $1 / 12$ oil immersion and No. 2 Zeiss E.P.

(a) Red corpuscle in a capillary.

(b) Endothelial cell of capillary wall.

(c) Growth cells undergoing karyomitosis.

(d) Growth cell with protoplasmic processes and vacuolation.

The whole specimen was placed for 24 hours in 4 per cent. formaldehyde, after which all but a small portion of the mass was transferred to Muller-formol solution, in several changes of which it was fixed for over six weeks. Sections of the portion fixed in formalin were unsatisfactory, as the tissue appeared to be incompletely fixed. Part of the mass fixed in Muller-formol was embedded in paraffin in the usual manner, and from this sections were prepared and stained with Ehrlich's haematoxylin and eosin, with Weigert's iron haematoxylin and van Gieson's picric acid fuchsin counterstain, and thirdly with Pappenheim's stain.

Microscopic examination.-Sections show that the mass is 
composed of cells with large round, oval or kidney-shaped nuclei, and a fairly abundant cell protoplasm (Fig. 7). The nuclei contain one or two and often three large nucleoli and a rather openwork chromatin pattern of coarse threads. The individual cells are, many of them, round and free, some show protoplasmic processes, and some, where packed closer together, show a polygonal form. Here and there vacuoles are present in the protoplasm. The tissue is evidently in a state of active proliferation, for mitotic figures and cells with double nuclei are not uncommon. Pappenheim's stain reveals no plasma cells. Delicate blood capillaries are seen throughout the section and very sparsely scattered collagen-fibre supporting tissue. The latter is more obvious in the periphery of the mass, presumably where the cells are in process of invasion of the orbital tissues. There is no definite pattern or arrangement of the cells in the recurrent mass as in the original growth. (The drawing represents the appearance of a few of the cells alongside of a capillary.) Section of the posterior end of the optic nerve shows degeneration of the nerve bundles, and an increase of fibrous tissue between these. Weigert's elastic stain reveals marked hypertrophy of the elastic coat of the intima of the central artery. There is no evidence of new growth within or around the nerve.

Further progress of the case.-The skin flaps healed by first intention except for a small area in the depth of the orbit, which remained as a granulating surface on the bone until the end of November, 1921. By the end of November there was a granulating surface $2.0 \mathrm{~mm}$. in diameter. The patient at this date appeared in good health.

In December, 1921, the blood was examined again, and in a differential white cell count showed only an increase of hyaline cells, as already mentioned.

\section{Differential diagnosis}

Clinical investigation, coupled with the pathological examination of the excised eyeball and of the recurrent mass in the orbit suggests - various possibilities, of which some can quickly be abandoned.

1. Granuloma or chronic inflammation.-The history of syphilitic disease of the, nose and the presence of a positive Wassermann reaction offered a possible explanation of the clinical condition. In the histological preparations a first glance at the scattered distribution of the cells within the anterior chamber supported the possibility of a chronic inflammation. However, the minute examination of the cells fails to reveal any that are typical of inflammation, acute or chronic, apart, perhaps, from some of the spindle-shaped cells. 
2. Lymphoma or lymphosarcoma.-Cases of these conditions in which tumours of considerable size have developed in the subconjunctival tissue, and in which recurrence took place in the orbit after enucleation of the eyeball, have been described by Coats $^{(1)}$, and by Casolino( ${ }^{(2)}$. In these, however, the primary tumour or tumours have displayed themselves in or near the typical lymph-bearing area, namely, at the fornix conjunctivae. Furthermore, in both the original growth and in the recurrences histological examination has always revealed a definite fibrous stroma. Thirdly, in lymphoma and lymphosarcoma the predominant cell has had some relationship in structure to a lymphocyte, whereas in the tumour under consideration the round cells are larger than cells of the lymph type and, particularly in the orbital recurrent mass, have a cell body of considerable size.

3. Leucosarcoma.-This group of tumours has a structure somewhat similar to the preceding, but is associated with a leucaemic condition of the blood ${ }^{(23)}$. In the case described, the blood showed no greater change than an excess of hyaline cells.

4. Carcinoma.-The general histological appearance in metastatic carcinoma of the choroid ${ }^{(17)}$ is somewhat similar to that of the choroid in the case under consideration. The following points, however, weigh against the diagnosis of secondary carcinoma with extraocular extension:-(a) The growth, for inflammatory cause has been excluded, first made itself evident in an epibulbar position just above the limbus. At this time the vision of the affected eye was good, and according to the patient was only noticed to fail between 6 and 7 months later; $(b)$ the extraocular mass of growth at this site was more extensive than at any part of the choroid; $(c)$ the minute structure of the growth bears a much greater resemblance to a sarcoma than to a carcinoma. Also the histological appearance of the epibulbar mass bears no relationship to surface epithelium or glandular structure in the orbit. Hence the diagnosis of primary epibulbar or of metastatic. choroidal carcinoma may be excluded.

5. Endothelioma.-Some of the cells in the epibulbar growth and in the orbital recurrence bear a slight resemblance to the so-called endothelial cell, but the majority of the nuclei stain much more deeply than endothelial cells, as shown in the coloured drawing of cells present in the orbital growth. In some parts of the sections made from the photoxylin block (Jordan's method), there is an appearance of the formation of spaces between the cells. Further, the very long spindle or rod-shaped nuclei seen in one small portion of the epibulbar growth, might conceivably be elongated endothelial cells cut on edge. The curved form of these nuclei and the presence of free red corpuscles between and among them is suggestive of a tendency on the part of the growth 
cells to form spaces, and to perform a function of endothelial cells $^{(28)}$. The criticism to be passed upon the first of these points is that there is also some space formation and separation of lamellae in the sclera in these paraffin-photoxylin sections, and that this space formation is not present in the celloidin sections. In the latter there is, however, the alveolar structure which is not uncommon in epibulbar sarcomatous growths ${ }^{(14)}$. To the second point it may be added that this crowded appearance of elongated nuclei is only seen in one small area, and to the third, that this area is particularly rich in capillaries and that the free red corpuscles may represent a small haemorrhage.

6. Sarcoma.- In the consideration of this arises again the question as to whether the growth is a primary epibulbar or a primary choroidal sarcoma. In favour of a diagnosis of primary choroidal sarcoma and against that of epibulbar may be adduced the following arguments :-

1. The inward extension of sarcoma from epibulbar growths is less common among recorded cases than the converse.

2. Lymph stream is probably the main cause of migration of sarcoma cells, according to Coats ${ }^{(25)}$, and it is probable that the main lymph flow is outwards in the direction of the venous blood flow.

3. Flat sarcoma of choroid or ciliary body is not inf requently of long duration, up to several years, before any ocular symptoms are noticed ${ }^{(24)}$. In the case described, vision was known to be good for two months after the patient first noticed the extraocular swelling, and was not found by the patient to have failed before six or seven months had elapsed.

4. Pathological examination of flat sarcomata occasionally reveal very extensive spread of growth in the anterior part of the uvea without involvement of the posterior part, and so without interference with the actively visual part of the retina, and without obvious loss of visual acuity. An example of this is Parsons' case of ring sarcoma ${ }^{(27)}$, a spindle-celled leucosarcoma involving the ciliary body and a large part of the iris, in an annular mass, but without extraocular extension.

On the other hand, in support of the diagnosis of primary epibulbar sarcoma there are the following facts :-

1. The first symptoms were referred by the patient to an epibulbar region.

2. The superior or original part of the epibulbar growth is more massive than any part of the choroidal growth.

3 . The vision of the affected eye was definitely tested and found to be good, $6 / 6$ with correction, two months after the recognition of the presence of the swelling, and was not noticed by the patient 
to deteriorate until more than six months later. This fact, as already shown, is not of very great value.

4. The diffuse distribution of the growth through the choroid has more resemblance to a secondary growth in this situation than to a primary. In this connection may be cited a case of primary epibulbar sarcoma with invasion of the choroid, reported by Verhoeff and Loring ${ }^{(19)}$, in which this point is emphasised. There is much resemblance between Verhoeff and Loring's case and the present case. It was shown conclusively that the former was primarily epibulbar. On the other hand, of 103 cases of primary sarcoma of the uveal tract, analysed by Lawford and Collins ${ }^{(5)}$, in 21 cases extension outwards through the sclera occurred. All of these outwards extensions were localized except five. In these five cases the orbit was filled with a large mass of growth, or, as in one, there was a fungating mass. These outward spreading sarcomata, then, primary in the choroid, presented a very different picture from that of the cases above described. Among seven cases described by Kerschbaumer ${ }^{(12)}$ as diffuse sarcoma of the eye there was none which had a distribution resembling this case.

5. Invasion of the deep scleral laminae by flat sarcoma of the choroid is common. In this specimen there is invasion of the outer layers but not to any extent of the inner sclerotic layers ${ }^{(14)}$.

6. The growth in this case is well supplied with delicate capillaries, whereas in the usual flat sarcoma there is generally a lack of vessels, except in the rare angeio-sarcoma.

7. Flat sarcoma is usually deeply pigmented ${ }^{(24)}$. In the case described, there is no trace of pigmentation in the epibulbar or orbital growth, and only a few streaks of pigment in the choroidal portions, obviously remnants of the pre-existing choroid pigment.

In several other points the case resembles that of a typical epibulbar sarcoma. The age of the patient was 53 years at the time of his first visit to the hospital. The average age at which this type of growth appeared in Verhoeff and Loring's series of 73 cases collected from the literature in 1903, was 51 years, although it had occurred in some cases at the ages of 8,11 , and 14 years. Whereas, the average age of cases with sarcoma of the uveal tract as tabulated by Parsons ${ }^{(15)}$, is 44.2 (Fuchs), 48.4 (Lawford and Collins), 48.7 (Pawel), in 259, 103 and 100 cases respectively. A history of trauma is not common, 6 in 73 cases $^{(19)}$ of epibulbar sarcoma. The site of origin of such tumours is usually at or near the limbus. The growth, as in this case, is relatively slow. The histological appearance is commonly that of rings or columns of cells in a somewhat alveolar formation ${ }^{(14,16)}$.

The cells are most often spindle-shaped, but may be round, and sometimes almost entirely large and multinucleated ${ }^{(20)}$. In sections of the case described, there are fairly frequent bi-nucleated 
cells. Although, as a rule, sarcoma penetrates the cornea less frequently than carcinoma, and usually rides over the cornea, as here to some extent, yet actual penetration through Bowman's membrane does occur ${ }^{(6,20)}$.

\section{Penetration of the eyeball (I) by epibulbar carcinoma}

The following cases of epibulbar carcinoma with penetration of the eyeball have been described :- Heyder ${ }^{(9)}$ reported an epibulbar carcinoma in a male of 55 years. In this, more than the anterior half of the globe was covered with growth, the cornea was perforated and the globe was partly collapsed. Reis' case ${ }^{(17)}$, showed a large orbital tumour which surrounded the greater part of the posterior half of the globe, with a metastatic adenocarcinoma which extended almost throughout the choroid. E. Treacher Collins ${ }^{(4)}$ described a specimen sent by Dr. Maddox, in which the carcinoma had spread through the substantia propria at the limbus, and by the perivascular lymphatics of the anterior ciliary vessels, to the canal of Schlemm. Extension also took place backwards into Tenon's capsule, and thence over the sclera back almost as far as the entrance of the long ciliary arteries. The growth permeated along lymph channels part of the way through the sclera. Collins also referred to similar cases of spread to the canal of Schlemm, and thence to the interior of the eye, reported by Parisotti, Remak, Caspar, Lagrange, and Delord and Reval.

Extensive non-penetrating carcinomata have been described by Heyder $^{(9)}$, Meyer ${ }^{(13)}$, Reis ${ }^{(17)}$, and Lagrange ${ }^{(26)}$. The first was in a woman of 52 years, and the growth covered the whole of the cornea and more than the anterior half of the globe. The globe itself was intact and not perforated. Meyer's case of carcinoma and the epibulbar sarcoma described in this paper might well have been confused clinically. The former showed a pale red nodular mass up to three $\mathrm{mm}$. in thickness which filled completely the outer half of the palpebral fissure and overlapped the cornea entirely except for a few millimetres on the nasal side. Reis described two cases of which one covered the greater part of the cornea and perforated Bowman's membrane in a small area, the second was referred to as a peribulbar epithelioma and overlay the front of the globe. Lagrange's case was one in which the whole of the globe was encircled by carcinomatous growth in a manner similar to the spread of the sarcoma above described, but the former did not penetrate the eyeball.

These cases of carcinoma do not pretend to exhaust the literature of the subject. They serve for comparison with epibulbar sarcoma. Inward spread of growth is commoner in carcinoma than in sarcoma ${ }^{(14)}$. 


\section{Penetration of the eyeball (II) by epibulbar sarcoma}

The only cases that were found in the literature with a resemblance to this case in their extension into the globe are those of-

1. Verhoeff and Loring(19).

2. v. Michel (quoted by the above from Bericht über Verhandlungen des IX Internat. Kongress, Utrecht, 1899).

3 . Kerschbaumer ${ }^{(12)}$.

The first of these has some clinical as well as pathological similarity with that which is under consideration, and from the aspect of diagnosis is worth quoting in some detail. The patient was a man, aged 40 . Two years previous to his visit to hospital he had noticed a small red spot, the size of a pin head, above the cornea. One year later he was seen at hospital with a small round bluish swelling, which was thought to be a staphyloma. Finally, he was seen again, and on this occasion he had a rounded bluish swelling above the cornea, a smaller similar swelling below, and a third-the largest- $12 \mathrm{~mm}$. by $9 \mathrm{~mm}$. by $6 \mathrm{~mm}$. anteroposteriorly, projecting forward from the limbus on the nasal side. In this eye the ciliary body and part of the iris were replaced by growth, and the choroid contained a flat layer of growth extending as far back as the disc on the nasal side, upwards almost to the upper pole and downwards almost to the lower pole. The growth proved to be a spindle-celled moderately-pigmented sarcoma.

In the second case, that of $\mathrm{v}$. Michel, the growth is quoted by Verhoeff and Loring as extending from the equator, above, forwards on to the upper part of the cornea. The iris and choroid were invaded throughout by growth cells. The patient is stated to have been a man aged 63 years, and to have noticed the swelling in the ciliary region first of all.

Kerschbaumer described a small round-celled sarcoma, with some larger polyhedral cells in its structure, and with haematogenous pigmentation. It was wide based, situated on the temporal side of the eye and over sclera and cornea. It penetrated to the canal of Schlemm, and thence through the ligamentum pectinatum to the ciliary body and root of the iris. The same author described two other epibulbar sarcomata with penetration of the globe, but in collapsed eyes.

Verhoeff and Loring quote Kolaczek* and Adamuck as having had each one case of epibulbar sarcoma with penetration of the globe. In the former the globe was found to be full of growth, in the latter there was a small penetration near the equator.

There are four other aspects of this subject that are of especial

* Quoted by Verhoeff and Loring from Deutsch. Zeitschr. f. Chirurgie, Bd. XII, 188, S. 75, and Arch. f. Augenheilk,, Bd. XI, S. 19, 1881. 
interest. The occurrence of epibulbar sarcoma is, as is well known, extremely rare.

Crigler $^{(6)}$ reports the occurrence of only 4 among 100,000 cases of conjunctival affections.

Verhoeff and Loring ${ }^{(19)}$ mention two in 44,719 eye cases, with 10 choroid sarcomata and 6 epibulbar carcinomata.

During the last two years, 1920, 1921, there has been one case of pigmented epibulbar tumour at the Central London Ophthalmic Hospital, out of a total of 26,152 eye cases. This tumour was classed by the writer as a melanotic sarcoma, although in one place its superficial cells were very closely associated with the conjunctival epithelium.

During the years 1920,1921, there has been this one case of epibulbar sarcoma, which is of a particularly unusual type, at the Royal London Ophthalmic Hospital, and one case of epibulbar carcinoma. The latter case occurred in 1920 , while Mr. M. H. Whiting was Curator. During this time nearly 100,000 separate patients attended.

The proportion of these epibulbar sarcomata to sarcoma of the eye as a whole is given by Kerschbaumer as 9 out of a total of 67 cases.

The origin of these growths is, naturally, rather speculative. There is evidence which is strongly suggestive that epibulbar carcinomata arise in some cases from naevi, pigmented as in $\mathrm{v}$. Sicherer's case ${ }^{(18)}$, or unpigmented. It is well known that xerodermia pigmentosa frequently terminates with carcinoma of the skin. Greeves reported a tumour on the globe of this origin ${ }^{(29)}$.

As for epibulbar sarcomata, it is probable that some arise from dermoids, dermo-lipomata or from melanomata-referred to simple pigmented connective tissue tumours. A few have trauma as their actual or their exciting cause ${ }^{(14)}$.

Malignancy and treatment.- There can be no doubt that the malignancy of epibulbar growths, be they carcinomata or sarcomata, varies to an enormous extent. At one extreme there is a case such as Wood' ${ }^{(22)}$, in which there was a history of a swelling on the upper aspect of the globe, noticed 5 months prior to operation in a girl of 15 years of age. Already there was an enlarged pre-auricular gland. The child died 3 months after operation with abdominal symptoms suggestive of metastasis. At the other extreme is such a case as that reported on several occasions by Jessop ${ }^{(11)}$. The patient was a woman, Emily J: G., who suffered from the appearance of a localized melanotic sarcoma at or near the limbus at intervals of a few years. These tumours were excised locally, and the base was usually cauterized. In this way the patient was watched for 13 years.

Collins ${ }^{(30)}$ referred to three cases of sarcoma, each of which was 
treated by local excision of the growth. In the first, in which the pathological diagnosis was confirmed by Mr. Butlin, the patient was watched for 15 years without the appearance of any recurrence. The others were watched for 7 years, and several years respectively without reappearance of growth.

Collins $^{(30)}$ also reported a case of recurrent epibulbar sarcoma sent him by Mr. Cresswell, in which the rather wide-based growth was excised as far as possible and the base treated with three applications of radium. The vision of the affected eye was $6 / 6$. The operation was in September, 1917, and in March, 1918, there was no sign of recurrence. A note received from Mr. Cresswell, January 11, 1922, stated, "I have not seen Annie W. for some time now, so conclude that she is keeping well."

Paton $^{(3)}$ referred to a patient with recurrent sarcoma which was excised locally, and stated that the patient was well 16 months later.

Storey ${ }^{(3)}$ mentioned a case with extensive secondary growths and abdominal metastasis, which caused death within about two years of the date of operation.

Heckel ${ }^{(8)}$ employed a very large number of doses of $\mathrm{X}$-rays at short intervals, without excision, on a case of epibulbar sarcoma. The pathological report was made by Dr. Proescher. The patient was free from recurrence 5 years after his first visit.

Jean ${ }^{(10)}$ removed a sarcoma locally, on account of blindness in the other eye, but the growth recurred. Wolfe ${ }^{(21)}$ advocates immediate histological examination of the tumour at the time of local excision, and enucleation if the growth prove to be sarcoma. Verhoeff and Loring take a pessimistic view of every case of epibulbar sarcoma. Crigler quoted 12 cases from the literature. Of these 1 (Tweedy's) was fatal in 2 years. Five were watched and were free from recurrence respectively for 10 months, 1 year, 1 year, $1 \frac{1}{4}$ years, 4 years.

The following results of operation on epibulbar carcinoma are of interest, in cases which have been followed up for considerable periods.

Meyer ${ }^{(13)}$, local excision. Recurrence and further excision. No recurrence during 18 months. .

Jessop (11), local excision. Watched for 22 years.

Collins $^{(4)}$ : (1) Radium treatment, one application only. The patient was well 5 months later, and died, according to recent information, without recurrence (date not known); (2) local removal. Pathological section by Coats. Well for 10 years without recurrence.

No hard and fast rule can be laid down for the treatment of either epibulbar carcinoma or sarcoma. Crigler's ${ }^{(7)}$ three maxims should prove a useful guide :- 
1. If the growth is freely movable with the conjunctiva over the underlying structures, with slow or imperceptible growth, remove locally.

2 . If the least adherent, remove the globe and considerable margin of conjunctiva around. Apply radium.

3. If first seen with large growth, and history of rapid extension - exenterate the orbit.

I would venture to modify No. 2 . If the growth is small-up to not more than a few millimetres in diameter of base-and yet is adherent, excise as freely as possible and apply radium. If the growth is large and the least adherent, enucleation should be performed.

\section{(To be Continued.)}

\section{THE BOWMAN LIBRARY}

BY

$$
\text { R. R. JAMES (Librarian) }
$$

LONDON

SwIFT is reputed to have said that a good library always made him melancholy, where the best author is as much squeezed and as obscure as a porter at a coronation. When I first took over the duties of Librarian, a year ago, I, like Swift, felt melancholy, not on account of the squeezing of our books, though our space of course is limited, but because of the many gaps in our sets of periodicals, which gaps it seemed almost impossible to fill up. When the Ophthalmological Society of the United Kingdom was founded in 1880, one of the main objects in the minds of the founders was the formation of an adequate ophthalmological library; Sir William Bowman presented the first bookcases, very solid and good light oak bookcases they are, and annually until his death gave a sum of money for the purchase of books; besides this his name figures on our balance-sheet in every year up to 1902 as the donor of a sum of money, usually $£ 50$, to the Society's funds. Every year from 1885 to 1913 a sum of money, usually either $£ 20$ or $£ 40$, was voted by the Council from the funds of the Society, for the upkeep of the library. Important gifts of books have been made from time to time by ophthalmic Surgeons, such as Mr. Nettleship, Mr. Jessop, Mr. Power and Sir Anderson Critchett, and the library has steadily grown, under the fostering hands of its former librarians, from small beginnings to be one of the finest collection of books on purely ophthalmological subjects in existence. 